\title{
Erratum to: Effect of the Simulation Box Size and Precipitant Concentration on the Behavior of Tetragonal Lysozyme Dimer
}

\author{
Yu. V. Kordonskaya ${ }^{a, b, *}$, V. I. Timofeev ${ }^{a, b}$, Yu. A. Dyakova ${ }^{a, b}$, M. A. Marchenkova ${ }^{a, b}$, \\ Yu. V. Pisarevsky ${ }^{a, b}$, and M. V. Kovalchuk ${ }^{a, b}$ \\ a Shubnikov Institute of Crystallography, Federal Research Center "Crystallography and Photonics," \\ Russian Academy of Sciences, Moscow, 119333 Russia \\ ${ }^{b}$ National Research Center "Kurchatov Institute," Moscow, 123182 Russia \\ *e-mail: yukord@mail.ru
}

Received November 8, 2021; revised November 8, 2021; accepted November 8, 2021

DOI: $10.1134 / \mathrm{S} 1063774521070282$

The article "Effect of the Simulation Box Size and Precipitant Concentration on the Behavior of Tetragonal Lysozyme Dimer”, written by Yu. V. Kordonskaya, V. I. Timofeev, Yu. A. Dyakova, M. A. Marchenkova, Yu. V. Pisarevsky, and M. V. Kovalchuk, was originally published electronically in Springer-Link on 25 May 2021 without Open Access. After publication in volume 66 , issue 3 , pages $525-528$ the authors decided to make the article an Open Access publication. Therefore, the copyright of the article has been changed to (C) The Author(s) 2021 and the article is forthwith distributed under the terms of a Creative Commons Attribution 4.0 International License (http://creativecommons.org/licenses/by/4.0/, CC BY), which permits use, duplication, adaptation, distribution and reproduction of a work in any medium or format, as long as you cite the original author(s) and publication source, provide a link to the Creative Commons license, and indicate if changes were made.

The original article can be found online at https://doi.org/10.1134/S106377452103010X 